\title{
The Differences of Malondialdehyde Serum Level, Expression of Tumor Necrosis Factor Alpha and Vascular Endothelial Growth Factor, and the Area of Endometriotic Implants in Administration of Kebar Grass Extract (Biophytum petersianum) and Green Tea Extract (Camelia sinensis) to Mice
}

\author{
Yuli Trisetiyono ${ }^{1}$, Noor Pramono ${ }^{1}$, Syarief Thaufik Hidayat ${ }^{1}$, Widjiati2 \\ ${ }^{1}$ Reproductive Endocrinology and Infertility Division, Department of Obstetrics and Gynecology, Faculty of \\ Medicine, Diponegoro University, Indonesia \\ 2Department of Embryology, Faculty of Veterinary Medicine, Airlangga University, Indonesia
}

\begin{abstract}
The pathological pathway of endometriosis remains unclear and involves complex etiologies. Increased oxidative stress is understood to be related to this disease. Oxidative stress produces reactive oxygen species, causes inflammation that is characterized by recruiting lymphocytes and phagocyte activation, produces cytokines that induce oxidation enzyme, and supports epithelium growth. Oxidative stress conjointly will increase angiogenesis and promotes the proliferation of endometriosis tissue within the peritoneal cavity. Kebar grass and green tea contain high antioxidants, are expected to extend antioxidant defense leading to reduced oxidative stress, inflammation, angiogenesis, and reduced endometriosis tissue implants. The objective is to analyze the consequences of Kebar grass and green tea extract to MDA serum level, TNF- $\alpha$, and VEGF expression, and the area of the endometriotic implants in the mice models. The study was an experiment designed. It has been conducted within the Department of Obstetrics Gynecology, Faculty of Medicine Diponegoro University and Faculty of Veterinary Medicine Airlangga University. Twenty-one mice were divided into three groups, i.e., the first group of mouse models was given Kebar extract $3 \mathrm{mg} /$ day; the second group was assigned green tea extract $1.1 \mathrm{mg} /$ day; therefore the third group was a control group contains the untreated endometriosis mice. Each treatment was given for fourteen days. MDA serum level was measured by specto-photometric examination, the area of the endometriotic implants was measured by computer tracing technique, whereas TNF- $\alpha$ and VEGF expression of endometriotic implants were measured by IHC using Rammele Scale Index (ImmunoReactive Score). The MDA serum levels of the groups treated with Kebar grass extract and green tea extract were significantly lower than the control group $(0.09 \pm 0.022 \mathrm{mmol}, 0.07 \pm 0.019 \mathrm{mmol}$, and $0.30 \pm 0.062 \mathrm{mmol}$, respectively; $\mathrm{p}=0.001$ ). TNF- $\alpha$ expression of the groups supplied with each treatment also lower than the control groups $(2.43 \pm 1.521,3.66 \pm 1.422$, and $7.26 \pm 2.898$, respectively; $\mathrm{p}=0.002)$. However, VEGF expression was not significantly different between Kebar grass extract group, green tea group, and the control $(4.34 \pm 2.402$, $4.57 \pm 1.998,7.40 \pm 3.495$, respectively; $\mathrm{p}=0.089$ ). Finally, the area of the endometriotic implants of the mice models administered with all treatment was smaller than the control group $(0.01 \pm 0.025 \mathrm{~mm} 2,8.76 \pm 18.776$ $\mathrm{mm} 2$, and $34.80 \pm 13.079 \mathrm{~mm} 2$, respectively; $\mathrm{p}=0.003$ ). Conclusion: Kebar grass extract, as well as green tea extract administration to endometriosis model mice, resulted in lower MDA serum level and TNF- $\alpha$ expression, smaller the area of endometriotic implants compared, but not resulted in a significant difference of VEGF expression.
\end{abstract}

Keywords: endometriotic implants; green tea extract; kebar grass extract; malondialdehyde; tumor necrosis factor alpha; vascular endothelial growth factor.

\section{INTRODUCTION}

Endometriosis is a common gynecological illness that is defined by the expansion of endometrial tissue outside the womb cavity. Endometriosis is closely associated with chronic pelvic pain and female infertility (Fritz et al., 2010). The pathological process of endometriosis

*Corresponding author : Yuli Trisetiyono

Email : yulitrisetiyono@fk.undip.ac.id remains unclear and involves complex etiologies. Increased oxidative stress (OS) is known to be associated with this disease. The oxidative stress will increase angiogenesis and supports the proliferation of endometriosis tissue within the peritoneal cavity. (Sekhon et al., 2013) Vascular endothelial growth factor (VEGF), the most critical angiogenesis agent is concerned in the progression of ectopic lesions that is indicated by the presence of various vascularisation, and the expression of 
VEGF receptors in deep infiltrating endometriosis. (Kralickova et al., 2016; Rocha et al., 2013) Oxidative stress produces reactive oxygen species (ROS), causes inflammation which is characterized by recruiting lymphocytes and macrophage activation, produces cytokines that induce oxidization enzyme, and supports epithelial growth. (Sourial et al., 2014) Tumour necrosis factor alpha (TNF- $\alpha$ ) also plays an essential role in the development of endometriosis disease. TNF- $\alpha$ regulates the secretion of inflammatory mediators and the invasion of epithelial cells. (Grund et al., 2008; Sanchez et al., 2015) Besides, the ectopic endometrial tissue, particularly peritoneum can survive because of estrogen support and resistance to progesterone, further as blood supply formed by angiogenesis. Exaggerated ROS within the peritoneum causes an inflammatory reaction that later may pass through surveillance because of the immune system dysfunction. Endometriosis implants have anti-apoptotic and pro-proliferative properties that let the lesion grow and unfold. (Sourial et al., 2014; Harada et al., 2007; Fritz et al., 2011) Many herbs were examined to be an alternative treatment for endometriosis, because of its high antioxidant capacity. Kebar grass could be a medicative plant that has been empirically used by the Papuan to support fertility and relieve catamenial disorders such as irregular cycle and pain (Sadsoeitoeboen et al., 2005). This herb is the source of phytochemical substances that typically have potent antioxidant activity, and they are believed to play a role in antioxidant defense mechanisms against OS (Alok et al., 2014). Some studies have found that Kebar grass contains alkaloid compounds, steroids, flavonoids, triterpenoids, glycosides vitamin E, mineral elements and amino acids, which are potential sources of antioxidant (Sembiring et al., 2014; Sukarsono et al., 2012). Green tea is one kind of tea, could be a favorite consumed beverage worldwide. It contains some catechins, notably (-)epigallocatechin gallate (EGCG), which have potential anti-angiogenic and anti-oxidation properties to inhibit the expansion of endometriosis (Man et al., 2012). This research examined endometriosis mice models fed with Kebar grass extract (KGE) for fourteen days, to be compared with mice received green tea extract (GTE) and the control group without any treatment. It aims to evaluate the efficacy of KGE and GTE to extend the antioxidant defense leading to a decrease of oxidative stress, inflammation, and angiogenesis in mice models; that inhibit endometriotic tissue extension.

\section{METHODOLOGY \\ Materials}

This research employs experimental study in mice. The samples were three months old Balb/c female mice weighing 15-20 grams. Twenty-one mice were concerned within the research throughout the stage of sample calculation. Kebar grass and green tea extract were processed in Pharmacy Laboratory of Diponegoro University using an ethanol solvent maceration technique. Human endometrial tissues were obtained from women who underwent an operation due to benign womb diseases, double-washed with phosphate-buffered saline (PBS) and mixed as crude fragments in PBS with penicillin $200 \mathrm{IU} / \mathrm{ml}$ and streptomycin 200 $\mu \mathrm{g} / \mathrm{ml}$. Endometrial tissue solution of $0.1 \mathrm{ml}$ was injected intraperitoneally using the $16 \mathrm{G}$ needle to each mouse, followed by injection of 0.2 $\mathrm{ml}$ cyclosporine-A i.m and $5.4 \mu \mathrm{g} 17 \beta$-estradiol i.m on day one and day five (Hendarto et al., 2014).

\section{Methods}

The study was conducted in Reproductive Endocrinology \& Infertility Division of Ob/Gyn department, School of Medicine, Diponegoro University and Faculty of Veterinary Medicine of Airlangga University. Mice divided into three groups. Every group consisted of seven endometriosis mice models: the first group was given with KGE, the second group received GTE, the third group was a control without any treatment. Every treatment was given for 14 days. Starting from day 14 until day 28, the first group received $3 \mathrm{mg} /$ day $\mathrm{KGE}$, the second group received $1.1 \mathrm{mg} /$ day GTE, whereas the control group received daily feed solely. All of the mice were sacrificed on day 28, using a high concentration of ether, whereas taking blood samples from their hearts for malondialdehyde (MDA) serum examination by spectrophotometry. Mice were killed by cervical dislocation, followed by opening the peritoneal cavity to measure the area of endometriosis implants by tracing computerized (figure 1). Then, peritoneum with endometriotic implants was sent to the laboratory for immunohistochemical examination of Tumor Necrosis Factor Alpha (TNF- $\alpha$ ) dan Vascular Endothelial Growth Factor (VEGF) expression referring to the Rammele Scale Index (ImmunoReactive Score) (Nowak et al., 2007). All obtained data were analyzed statistically using SPSS, and a significant difference was determined by $\mathrm{p}<0.05$. 


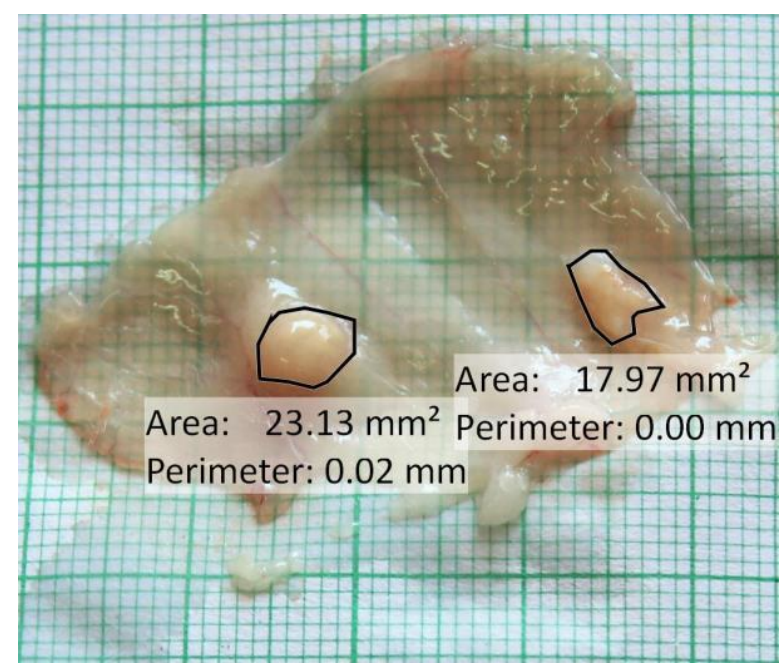

Figure 1. Endometriotic implants in mice peritoneum.

Table I. MDA levels of endometriosis mouse models

\begin{tabular}{|c|c|c|}
\hline Groups & Mean (SD) & p* \\
\hline KGE & $0.09 \pm 0.022$ & \\
\hline GTE & $0.07 \pm 0.019$ & 0.001 \\
\hline Control & $0.30 \pm 0.062$ & \\
\hline
\end{tabular}

*Kruskal-Wallis test

Table II. Comparison of MDA serum levels among the study groups

\begin{tabular}{ll}
\hline Compared groups & $\mathbf{p}^{*}$ \\
\hline KGE vs GTE & 0.124 \\
KGE vs control & 0.001 \\
GTE vs control & 0.001 \\
\hline
\end{tabular}

* Mann-Whitney test

\section{RESULTS AND DISCUSSION}

MDA serum level

The means of MDA serum levels in KGE group, GTE group, and the control group were $0.09 \pm 0.022$ mmol, $0.07 \pm 0.019 \mathrm{mmol}$, and $0.30 \pm 0.062 \mathrm{mmol}$; respectively. The KruskalWallis statistical test showed a significant difference among the study groups $(p=0.001)$ (Table I). In comparison among groups, a post hoc test Mann-Whitney obtained means of MDA serum levels of the mice in all treatment groups were significantly different compared to the control group ( $\mathrm{p}=0.001$ and 0.001) (Table II).

Recently, several studies have shown the role of oxidative stress and antioxidants within the pathogenesis of endometriosis (Gupta et al., 2010). That has led several recent studies tried to evaluate the role of antioxidants in the treatment of endometriosis. Kebar grass is one of Indonesia's medicative plants originally from Papua and historically used as fertilizing support since a long time ago. It was also believed to treat menstrual disorders such as irregular cycles and menstrual pain (Sadsoeitoeboen et al., 2005). Kebar extract contains biflavones and flavonoids that will increase the conversion of estradiol to estrone, inhibit aromatization activity, and induce caspasemediated cell death in cancer cells and endometriosis. Kebar grass also contains vitamin C, vitamin E and other compounds with natural antioxidant activity (Sembiring et al., 2014). Kebar grass could have an essential role within the reproductive system because of its secondary substance from flavonoids, that belongs to phytohormones that may have an effect on reproductive hormones (Sukarsono et al., 2012). Green tea has a significant chemical component called EGCG which has been shown high antioxidant capacity and also demonstrated anti-angiogenic capability. It may also represent 

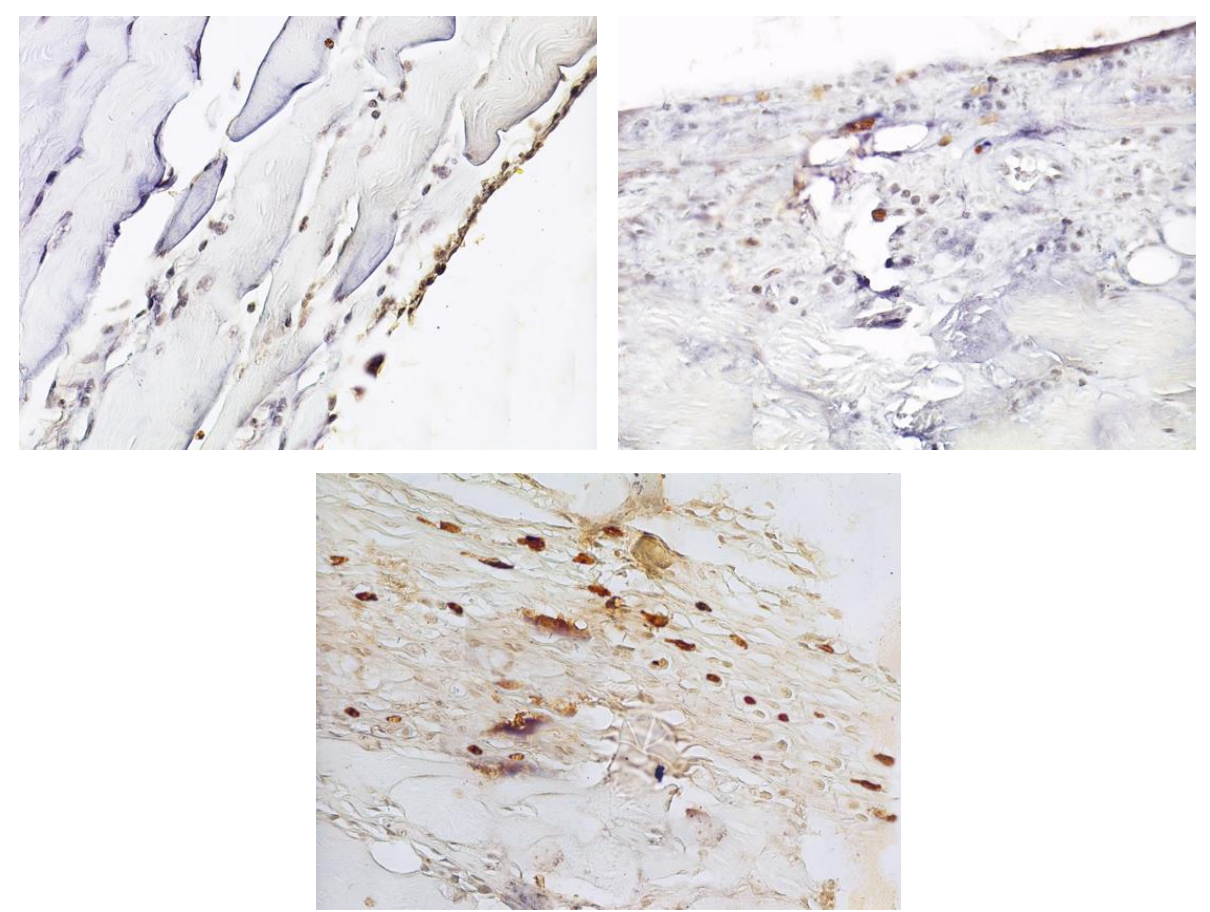

Figure 2. Histochemical immunostaining of TNF- $\alpha$ expression among study groups. The expression of TNF- $\alpha$ in granulation tissue is indicated by chromogen brown color (arrow). The highest intensity appeared in the control group (Nikon H600L microscope; 300 megapixel DS camera; 1000x magnification).

a promising therapeutic agent in the treatment of endometriosis (Xu et al., 2009; Xu et al., 2011; Laschke et al., 2008).

We found MDA serum level in KGE or GTE group was lower compared to the control. The chance that antioxidant capacity altogether three treatments would strengthen the performance of endogenous antioxidant defenses against OS, leading to reduced MDA as an OS product. The results are relevant to another study provided curcumin $24 \mathrm{mg}$ /day for 14 days supplementation as an antioxidant to the mice model of endometriosis and found lower ovarian MDA titer than the control group (Panjaitan et al., 2012). The previous study administered varying doses of green tea catechin to $\mathrm{Pb}$-induced oxidative stressed mice. They found $22.5 \mathrm{mg} / \mathrm{kg} /$ day green tea leaves modulate oxidative stress in $\mathrm{Pb}$-exposed erythrocytes by decreasing MDA and increasing SOD enzyme activity (Sukina et al., 2013). During a double-blind experimental with pre-post test and control group, two capsules GTE supplementation for 30 days to fifty-seven elder people has remittent MDA significantly (Artika et al., 2016).

\section{TNF- $\alpha$ expression}

Immunohistochemical staining of peritoneal tissue in figure 2 showed the highest intensity of TNF- $\alpha$ expression has appeared in the control group. The means of TNF- $\alpha$ expression in peritoneal tissue of endometriosis mice of KGE group, GTE group, and the control group were $2.43 \pm 1.521$, 3.66 \pm 1.422 , and 7.26 \pm 2.898 , respectively. The Kruskal-Wallis statistical test showed a significant difference among the study groups ( $\mathrm{p}=0.003$ ) (Table III). In comparison among groups, a post hoc test Mann-Whitney obtained means of TNF- $\alpha$ expression in all treatment groups were significantly different compared to the control group ( $p=0.002$ and 0.002 ) (Table IV).

Endometriosis is a condition typically related to inflammatory disease. Several studies had discovered some cytokines and chemokines that were rising as crucial players in endometriosis pathobiology, TNF- $\alpha$ is one of the increasing inflammatory cytokines in endometriosis (Greene et al., 2017). TNF- $\alpha$ is a native proinflammatory mediator will activate nuclear factor $\kappa \mathrm{B}(\mathrm{NF}-\kappa \mathrm{B})$, and hypoxia-inducible factor (HIF)- $1 \chi$ signaling pathways, and then increase cyclooxygenase (COX)-2 expression in endometriosis (Wu et al., 2015). In our study, KGE and GTE administration to mice resulted in lower TNF- $\alpha$ expression in endometriotic tissue. Vitamin $\mathrm{C}$ and vitamin $\mathrm{E}$ in Kebar grass extract should be a potent antiinflammatory to decrease biomarkers like TNF- $\alpha$. These results corresponded with another study administered a mixture of vitamin E $1000 \mathrm{mg} /$ day 
Table III. TNF- $\alpha$ expression of peritoneal endometriotic tissue

\begin{tabular}{llll}
\hline & Groups & Mean (SD) & $\mathbf{p}^{*}$ \\
\hline KGE & & $2.43 \pm 1.521$ & \\
GTE & $3.66 \pm 1.422$ & 0.003 \\
Control & $7.26 \pm 2.898$ & \\
\hline
\end{tabular}

*Kruskal-Wallis test

Table IV. Comparison of TNF- $\alpha$ expression among the study groups

\begin{tabular}{lc}
\hline Compared groups & $\mathbf{p}^{*}$ \\
\hline KGE vs GTE & 0.275 \\
KGE vs control & 0.002 \\
GTE vs control & 0.002 \\
\hline
\end{tabular}

* Mann-Whitney test

and vitamin C 1000 IU/day for four weeks to the elderly who had fasting glucose disorder. They found remittent levels of isoprostane-8 and TNF- $\alpha$ (Rizzo et al., 2008). Inflammation is a pathophysiological manifestation of numerous diseases including tumors. Pro-inflammatory signals like TNF- $\alpha$ and IL-1, carcinogens, a tumor promoter, and lipoid mediators stimulate COX-2 transcription by many pathways. It let two main arachidonic acid regulative pathways, the NF- $\kappa B$ regulation of COX-2 transcription and therefore the mitogen-activated protein kinase (MAPK) route (Desai et al., 2018). Phytonutrients are secondary metabolites found in plants such as Kebar grass and green tea, and renowned for their antibacterial, antioxidant and radical scavenging properties. Inhibition of COX-2 is one of the many proposed mechanisms by which dietary phytochemicals including EGCG as the major biologically active polyphenolic flavan-3-ols flavonoid constituent in GTE, may prevent tumor growth. GTE attenuates lipid peroxidation and PGE2 accumulation by decreasing COX-2 activity and reduces the protein and mRNA expression levels of COX-2 and the mRNA expression of inflammatory cytokines: TNF- $\alpha$, IFN- $\gamma$, IL-6, IL-12, and IL-18 (Desai et al., 2018). This catechins increased cancer preventive activities, such as induction of apoptosis, and inhibition of cell growth and TNF- $\alpha$ which acts as an endogenous tumor promoter (Suganuma et al., 2016; Chen et al., 2015). Similarly, green tea polyphenols are potent antioxidants with crucial roles in regulating vital signaling pathways in chronic inflammatory disease include endometriosis. EGCG in GTE will block the activation of the NF- $\kappa B$ and the release of proinflammatory TNF- $\alpha$ in intestinal epithelia. The green tea polyphenols were able to inhibit NF- $\kappa B$ activation and release of TNF- $\alpha$ can be responsible for the anti-inflammatory effects of green tea consumption (Helieh et al., 2017; Lin et al., 2018).

\section{VEGF expression}

Immunohistochemical staining of peritoneal tissue in figure 3 showed the lowest intensity of VEGF expression has appeared in the GTE group. The means of VEGF expression on peritoneal tissue of endometriosis mice of KGE group, GTE group, and the control group were $4.34 \pm 2.402$, 4.57 \pm 1.998 , and 7.40 \pm 3.495 , respectively. However, the ANNOVA statistical test has been used due to normal data distribution did not found a significant difference among the study groups ( $\mathrm{p}=0.089$ ) (Table V).

The role of angiogenesis within the pathophysiology of endometriosis is indisputable. Indeed, endometriotic cells require an adequate blood supply to survive in their ectopic sites. Endometriotic lesions are generally characterized by a dense vascularisation that occurs through the angiogenesis process. Endometriotic implants will turn out cytokines and growth factors that regulate their proliferation and vascularisation. IL- $1 \beta$, the dominant IL-1 secreted by activated peritoneal macrophages, plays a crucial role within the neovascularization of endometriotic lesions. ${ }^{4}$ VEGF is the most outstanding and the most studied of angiogenic growth factors are known, that expressed in endometriotic lesions and discharged into the peritoneal fluid of patients with endometriosis, which acts as a potent, selective endothelial mitogen and survival factor. Curiously, highly active red endometriotic lesions contain the highest concentration of VEGF, and the level of VEGF peritoneal fluid correlates with the stage of endometriosis (Laschke et al., 2012). 


\section{Yuli Trisetiyono}
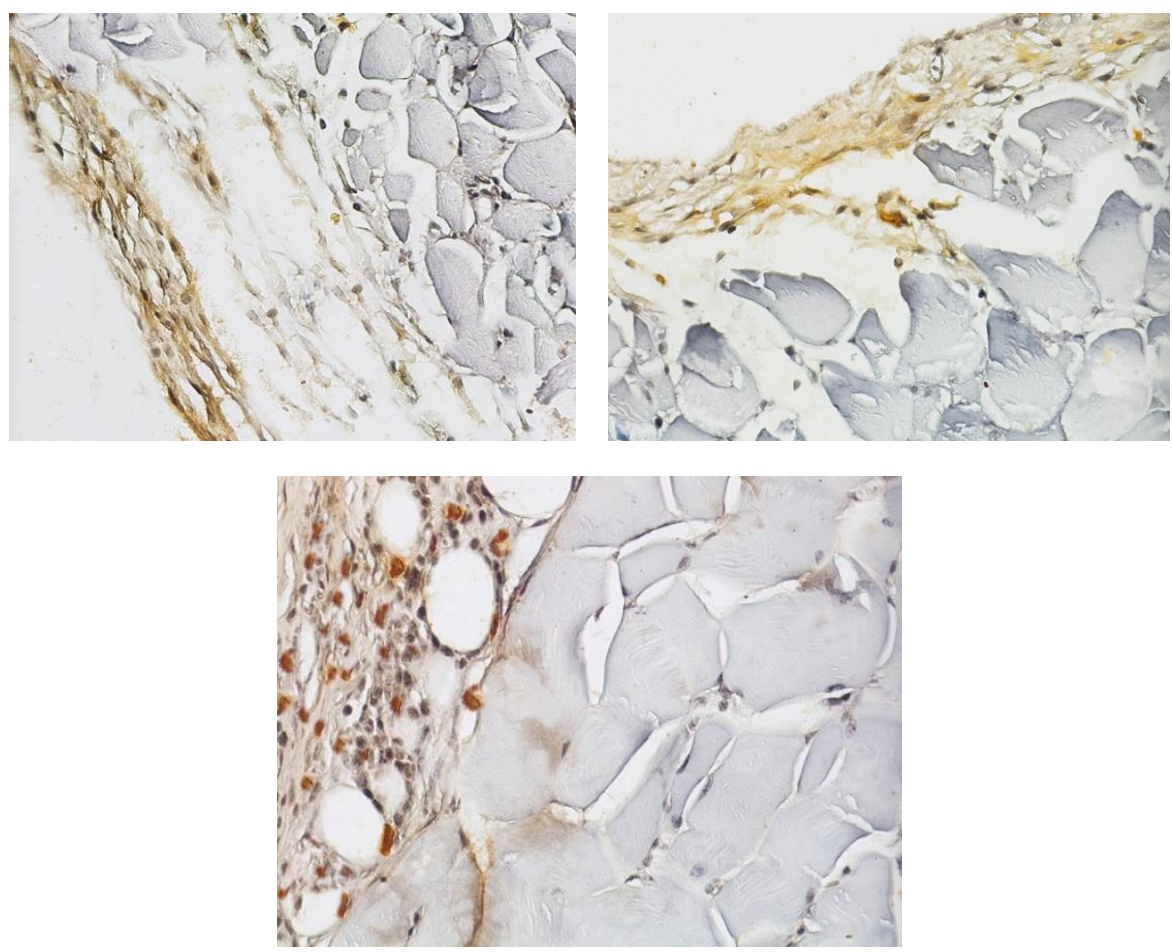

Figure 3. Histochemical immunostaining of VEGF expression among study groups. The expression of VEGF in granulation tissue is indicated by chromogen brown color (arrow). The highest intensity appeared in the control group (Nikon H600L microscope; 300 megapixel DS camera; 1000x magnification).

Table V. VEGF expression of peritoneal endometriotic tissue

\begin{tabular}{llll}
\hline & Groups & Mean (SD) & p $^{*}$ \\
\hline KGE & $4.34 \pm 2.402$ & \\
GTE & $4.57 \pm 1.998$ & 0.089 \\
Control & $7.40 \pm 3.495$ & \\
\hline
\end{tabular}

*oneway ANOVA test

Unfortunately, present study results showed VEGF expression in the endometriotic tissues of KGE or GTE group insignificantly different compared to the control. Whereas a previous study has shown that flavonoids and vitamin $\mathrm{E}$ can reduce VEGF expression in-vitro. ${ }^{33}$ Another study used phytopharmaca containing isoflavone genistein for six months to endometrial hyperplasia patients and located a significant reduction of VEGF, EGF and TGFB expressions. ${ }^{34}$ Similarly, other phytopharmaca studies found that isoflavone could also be anti-estrogenic and able to reduce VEGF level in endometrial cell culture. The higher dose of isoflavone and longer incubation tend to decrease the VEGF-A level. ${ }^{35}$ Some previous studies examined the advantages of GTE for endometriosis shown that green tea catechins particularly EGCG have anti-angiogenic effects on microvascular endothelium and suppressed the expansion and survival of experimental endometriosis in severely compromised immunodeficient mice. Mouse VEGFA mRNA expression in lesions with EGCG treatment was considerably down-regulated and decreased (Xu at al., 2009). A study analyzed the effect of EGCG on the eutopic endometrium, treated endometriosis model mice with $65 \mathrm{mg} / \mathrm{kg}$ EGCG daily for three days. Their research resulted in EGCG inhibits E2induced activation, proliferation and VEGF expression of endometrial cells (Laschke et al., 2008).

Endometriotic implants area

The means of endometriotic implants area in peritoneal tissue of the mice in KGE group, GTE group, and the control group were $0.01 \pm 0.025$ $\mathrm{mm} 2,8.76 \pm 18.776 \mathrm{~mm} 2$, and $34.80 \pm 13.079 \mathrm{~mm} 2$, respectively. The normality test showed data 
Table VI. The area of the endometriotic implants in the mice peritoneum

\begin{tabular}{|c|c|c|}
\hline Groups & Mean (SD) & $\mathrm{p}^{*}$ \\
\hline KGE & $0.01 \pm 0.025$ & \\
\hline GTE & $8.76 \pm 18.776$ & 0.005 \\
\hline Control & $34.80 \pm 13.079$ & \\
\hline
\end{tabular}

*Kruskal-Wallis test

Table VII. Comparison of endometrial implant areas among the study groups

\begin{tabular}{lc}
\hline Compared groups & $\mathbf{p}^{*}$ \\
\hline KGE vs GTE & 0.102 \\
KGE vs control & 0.003 \\
GTE vs control & 0.006 \\
\hline
\end{tabular}

* Mann-Whitney test

distribution of endometriosis implants area was not normal, so we used the non-parametric Kruskal-Wallis statistical test and found a significant difference among the study groups $(\mathrm{p}=0.005)$ (Table VI). In comparison among groups, a post hoc test Mann-Whitney obtained means of endometriotic implants area in all treatment groups were significantly smaller compared to the control group $(\mathrm{p}=0.003$ and 0.006) (Table VII).

Our study has discovered that every administration of KGE and GTE lead to smaller endometriotic tissue implants on mice peritoneum, compared with the control group. KGE contains vitamin $\mathrm{C}$, vitamin $\mathrm{E}$, and isoflavones (Gupta et al., 2010; Jackson et al., 2005; Agarwal et al., 2006), likewise as GTE; all treatments have components with potential antioxidants (Man et al., 2012; Das et al., 2013), decrease oxidative stress occurring within the pathology of endometriosis disease. A previous study has shown supplementation of the mixture of vitamin E 1200 IU and vitamin C 1000 mg daily to endometriosis patients for eight weeks reduced the level of pelvic pain (Santanam et al., 2014). Another study given vitamin C $500 \mathrm{mg} / \mathrm{kg}$ every two days intravenously to endometriosis model mice found a considerably smaller proportion of endometriosis implants than the control group (Erten et al., 2016). Moreover, Kebar grass extract also contains a high concentration of daidzein phytohormones may decrease the risk of advanced stage endometriosis by interacting with estrogen receptor two gene polymorphism (Tsuchiya et al., 2007). Green tea catechins and procyanidins have anti-oxidant activity. In a previous study, ECG and EGCG showed better antioxidant activity on lipid peroxidation (Man et al., 2012). In some researches, GTE with high antioxidant capacity incorporates a sensible result within the treatment of some tumors by concerned in cell mutation, proliferation, invasion, and caspase-mediated cell death. In fourteen days administration of EGCG to isolated rodent endometrial stromal cells and glandular cells in vitro, EGCG suppresses E2-stimulated activation and proliferation of endometrial cells and induces regression of the endometriotic lesions (Laschke $e t$ al., 2008).

\section{CONCLUSION}

Kebar grass and green tea extract administration to model mice result in lower MDA serum level and TNF- $\alpha$ expression, and the area of the endometriotic implants also smaller compared to the untreated mice. However, there was no difference in VEGF expression.

\section{ACKNOWLEDGMENTS}

The authors would like to acknowledge the excellent and efficient teaching staff of reproductive endocrinology and infertility subspecialist education of Diponegoro University/Kariadi Hospital, laboratory staff of pharmacy faculty of Diponegoro University, and also laboratory staff of the veterinary faculty of Airlangga University.

\section{REFERENCES}

Fritz MA, Speroff L. Endometriosis. In: Clinical gynecologic endocrinology and infertility. 8th ed. Philadelphia: Lippincott Williams \& Wilkins; 2010. p. 1221-48.

Sekhon LH, Agarwal A. Endometriosis and oxidative stress. In: Agarwal A, Aziz N, Rizk $B$, editors. Studies on women's health. New York: Humana Press; 2013. p. 149-67.

Kralickova M, Vetvicka V. Role of angiogenesis in endometriosis. Pathol Discov. 
2016;4(1):1-5

Rocha ALL, Reis FM, Taylor RN. Angiogenesis and endometriosis. Obstet Gynecol Int. 2013;2013:1-8.

Sourial S, Tempest N, Hapangama DK. Theories on the pathogenesis of endometriosis. Int J Reprod Med. 2014;2014:1-9.

Grund EM, Kagan D, Tran CA, Zeitvogel A, Starzinski-Powitz A, Nataraja S, et al. Tumor necrosis factor-a regulates inflammatory and mesenchymal responses via mitogenactivated protein kinase, $\mathrm{p} 38$, and nuclear factor B in human endometriotic epithelial cells. Mol Pharmacol. 2008;73:1394-404.

Sanchez G, Zubor P, Szunyogh N, Kajo K, Machalekova K, Biringer K, et al. [TNF-alpha serum levels in women with endometriosis: prospective clinical study]. Ces Gynekol. 2005;70(4):286-90.

Harada $\mathrm{T}$, Taniguchi $\mathrm{F}$, Izawa $\mathrm{M}$, Ohama $\mathrm{Y}$, Takenaka Y, Tagashira Y, et al. Apoptosis and endometriosis. Front Biosci. 2007;12:3140-51.

Fritz MA, Speroff L. Clinical Gynecologic Endocrinology and Infertility. 8th ed. Philadelphia: Lippincott Williams \& Wilkins; 2011.

Sadsoeitoeboen PD. [Benefits of Kebar Grass extract (Biophytum petersianum Klotzsch) on the reproductive appearance of white female mice]. Vol. Pasca Sarj. [Bogor]: Institut Pertanian Bogor; 2005.

Alok S, Jain SK, Verma A, Kumar M, Mahor A, Sabharwal M. Herbal antioxidant in clinical practice: a review. Asian Pac J Trop Biomed. 2014;4(1):78-84.

Sembiring B, Darwati I. [Identification of chemical components of accession of Kebar Grass (Biophytum petersianum) from Papua and Java]. Obat BPTR dan, editor. 2014;25(1):37-44.

Sukarsono. [Profile of secondary metabolite content of medicinal plants Biophytum petersianum and Biophytum sensitivum]. J Gamma. 2012;6(1):69-76.

Man GCW, Xu H, Wang CC. Green Tea for Endometriosis. Chaudhury K, Chakravarty $\mathrm{B}$, editors. Endometriosis. IntechOpen; 2012.

Hendarto H, Widjiati, Johari S. [Curcumin supplementation to improve oocyte maturation and results of in vitro fertilization in endometriosis mice]. Maj Obstet Ginekol. 2014;22(2):53-7.

Nowak M, Madej JA, Dziegiel P. Intensity of cox2 expression in cells of soft tissue fibrosacrcomas in dogs as related to grade of tumour malignancy. Bull Vet Inst Pulawy. 2007;51:275-9.

Gupta S, Chandra A, Kesavan S, Eapen D, Agarwal A. Oxidative Stress and the Pathogenesis of Endometriosis. In: Garcia-Velasco JA, Rizk BRMB, editors. Endometriosis: Current management and future trends. Cleveland: ClevelandClinic; 2010. p. 31-9.

Xu H, Lui WT, Chu CY, Ng PS, Wang CC, Rogers MS. Anti-angiogenic effects of green tea catechin on an experimental endometriosis mouse model. Hum Reprod. 2009;24(3):608-18.

Xu H, Becker CM, Lui WT, Chu CY, Davis TN, Kung $\mathrm{AL}$, et al. Green tea epigallocatechin-3gallate inhibits angiogenesis and suppresses vascular endothelial growth factor $\mathrm{C} /$ vascular endothelial growth factor receptor 2 expression and signaling in experimental endometriosis in vivo. Fertil Steril. 2011;96(4):1021-8.

Laschke MW, Schwender C, Scheuer C, Vollmar B, Menger MD. Epigallocatechin-3-gallate inhibits estrogen-induced activation of endometrial cells in vitro and causes regression of endometriotic lesions in vivo. Hum Reprod. 2008;23(1):2308-18.

Panjaitan BC, Sa'adi A, Hendarto H, Widjiati. Comparison of ovarial malondialdehyde (MDA) level between endometriosis rat given with and without curcumine supplementation. Maj Obstet Ginekol. 2012;20(1):30-4.

Sukina B, Prabowo GI, Suhartati S, Harianto N. [Green tea catechins (Camellia sinensis) against malondialdehyde and superoxide dismutase]. Indones J Clin Pathol Med Lab. 2013;19(2):92-7.

Artika FN, Susetyowati, Pramantara IDP, Lestari LA. [Effect of green tea extract (Camellia sinensis) to plasma malondialdehyde (MDA) level and hand grip strength of elderly]. 2016;13(2):59-66.

Greene AD, Lang SA, Kendziorski JA, Sroga-rios JM, Herzog TJ, Burns KA. Endometriosis : Where are We and Where are We Going? 2017;152(3):1-29.

$\mathrm{Wu} \mathrm{M}-\mathrm{H}$, Tsai S-J. Endometriosis and possible inflammation markers. Gynecol Minim Invasive Ther. 2015;4(3):61-7.

Rizzo MR, Abbatecola AM, Barbieri M, Vietri MT, Cioffi M, Grella R, et al. Evidence for antiinflammatory effects of combined administration of vitamin $\mathrm{E}$ and $\mathrm{C}$ in older persons with impaired fasting glucose: impact on insulin action. J Am Coll Nutr. 2008;27(4):505-11.

Desai SJ, Prickril B, Rasooly A. Mechanisms of 
phytonutrient modulation of Cyclooxygenase-2 (COX-2) and inflammation related to cancer. Nutr Cancer. 2018;70(3):350-75.

Suganuma M, Takahashi A, Watanabe T, Iida $\mathrm{K}$, Matsuzaki T, Yoshikawa HY, et al. Biophysical approach to mechanisms of cancer prevention and treatment with green tea catechins. Molecules. 2016;21(11):1-17.

Chen Z, Lin Z. Tea and human health: biomedical functions of tea active components and current issues. J Zhejiang Univ B. 2015;16(2):87-102.

Helieh SO. Chronic Inflammatory Diseases and Green Tea Polyphenols. Nutrients. 2017;9(6):561.

Lin Y-H, Chen Y-H, Chang H-Y, Au H-K, Tzeng C-R, Huang Y-H. Chronic Niche Inflammation in Endometriosis-Associated Infertility: Current Understanding and Future Therapeutic Strategies. Int J Mol Sci. 2018;19(8):2385.

Laschke MW, Menger MD. Anti-angiogenic treatment strategies for the therapy of endometriosis. Hum Reprod Update. 2012;18(6):682-702.

Schindler R, Mentlein $†$ R. Flavonoids and Vitamin E Reduce the Release of the Angiogenic Peptide Vascular Endothelial Growth Factor from Human Tumor Cells. Journals Nutr. 2006;136:1477-2006.

Granese R, Bitto A, Polito F, Triolo O, Giordano D, Santamaria A, et al. Genistein reduces angiogenesis and apoptosis in women with endometrial hyperplasia. Bot Targets Ther.
2014;5(5):27-32.

Jehanara, Sutrisno, Santoso S. [Effect of Genistein on Decreasing Vascular Levels of Endothelial Growth Factor-A in Endometriosis Cell Culture]. Maj Obstet Ginekol. 2014;22(2):94-100.

Jackson LW, Schisterman EF, Dey-Rao R, Browne R, Armstrong D. Oxidative Stress and Endometrosis. Hum Reprod. 2005;20(7):2014-20.

Agarwal A, Gupta S, Agarwal A, Krajcir N, Alvarez JG. Role of oxidative stress in endometriosis. Reprod Biomed Online. 2006;13(1):126-34.

Das K, Bhattacharyya J. Antioxidant Functions of Green and Black Tea. In: Preedy VR, editor. Tea in Health and Disease Prevention. London: Elsevier; 2013. p. 521-8.

Santanam N, Kavtaradze N, Murphy A, Dominguez C, Parthasarathy S. Antioxidant supplementation reduces Eendometriosis related pelvic pain in humans. Transl Res J Lab Clin Med. 2014;161(3):189-95.

Erten OU, Ensari T gba A, Dilbaz B, Cakiroglu H, Altinbas SK, Çaydere $\mathrm{M}$, et al. Vitamin $\mathrm{C}$ is effective for the prevention and regression of endometriotic implants in an experimentally induced rat model of endometriosis. Taiwan J Obstet Gynecol. 2016;55:251-7.

Tsuchiya M, Miura T, Hanaoka T, Iwasaki M, Sasaki $\mathrm{H}$, Tanaka T, et al. Effect of soy isoflavones on endometriosis: interaction with estrogen receptor 2 gene polymorphism. Epidemiology. 2007;18(3):402-8. 